\title{
INTERVIEW SECTION
}

María Goicoechea de Jorge*

Digital Literature is evolving and responding to the changes in digital technology, cyberspace's practices and a new generation of digital reading devices. For this issue of Texto Digital, we have had the chance to interview Mark C. Marino, probably one of the authors most sensitively responding to the new possibilities that the Web 2.0 places at the hands of writers. Creator of digital literature and other artistic digital objects, teacher of writing at the University of Southern California, and Director of Communication/Secretary for the Electronic Literature Organization, Mark C. Marino began studying digital literature in 1993 with George Landow during his bachelor's degree at Brown University. He then proceeded to write his doctoral thesis in Electronic Literature focusing on conversation agents, chatboxes at UC Riverside, becoming along the way a disciple of Katherine Hayles during studies at UCLA.

We discussed with him the nature of some of his works, his impressions regarding the past, present and future of digital literature, and his future projects. We hope this interview offers yet another piece of the configuration of the electronic literature field.

TD: When you talk about digital literature do you refer to digital literature in English only or do you also consider digital literature in other languages?

M. Marino: I first came across Spanish language digital literature when doing my PhD research, I studied under a teacher called Raymond L. Williams, a historian of Latin American Literature who has written several books on the tradition of Latin American Literature, from the Boom to the present. He was very interested in everything that had to do with

\footnotetext{
*Universidad Complutense de Madrid. mgoico@filol.ucm.es
} 
experimentation and I did a survey for his course on every work of digital literature in Spanish I came across, primarily focusing on Latin America. That is how I found the works of Jaime Alejandro Rodríguez (included in the second volume of the ELO Collection), but at the time there wasn't much else. During my search, I also encountered Juan Gutiérrez and started writing on the Literatronica system, which is what a show of hands is written on. Through Juan, I met Laura Borràs Castanyer. Later we collaborated together in a paper with Pablo Gervás, a computer scientist from the University Complutense.

But in general, I would say that the electronic literature I know is mostly in English. The ELMCIP directory and the most recent ELO collection has helped open up American understanding to electronic literature in other languages. Philippe Bootz has also done a lot of work in this respect. But even now Scott Rettberg, who directs the ELMCIP project, has mentioned that the ELMCIP directory is still full of American works. I find the field of electronic literature works like a guild, person to person. Scott Rettberg's network is full of American authors, he can easily compel them to enter text into the database; however, we don't have a lot of records of works that were done before the internet, in the early 1980 s, so many have been lost also. Much of the work of the ELMCIP group has been to recover and document those traditions in other languages across Europe. We need more scholars working on that.

TD: Questions regarding your digital literature production: Do you work alone or do you work in collaboration with a programmer?

M. Marino: Almost always. Even in pieces where I have written most of the code myself, I usually call in a friend for a consult. Keith Gustafson and Alan Laser have helped me on a number of projects, sometimes building the systems, sometimes offering creative technical support.

TD: Tell us about your work "A show of hands"... 
M. Marino: a show of hands is the story of a Mexican-American family that gets involved in immigration protests in 2006 in Los Angeles. To write it, I needed just the right system. When I was working in Storyspace in the mid ' 90 s, there were

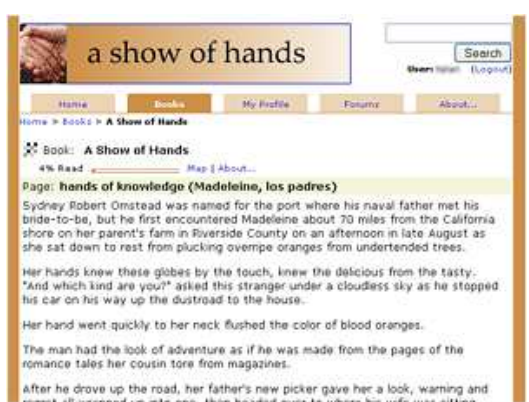
certain problems, which had also been identified by Espen Aarseth in Cybertext, connected with the idea that everything felt like an aporia, people not knowing how many pages they still had to read, feeling lost. Computer game designer Chris Crawford would say that you always ended up on these paths that were dead. So, Juan's system is meant to solve a lot of these problems. One thing it does is that you always see all of the pages.

TD: Could you explain to us how the "literatronica" system actually works and in which ways the hypertext adapts to the readers?

M. Marino: Yes, the Literatronica system works on an algorithm similar to the ones used in GPS devices to help you find the shortest path to get somewhere. Essentially, the writer in a Literatronica piece sets distances between lexias, or text passages, and as the system follows the reader's path through the hypertext, it recommends the next "nearest" lexias, constantly customizing this journey as the reader progresses.

All of the lexias are given spatial coordinates, and the recommendation is that the distance between two points is determined by narratological coherence, but you can set up any conditions you like. Literatronica solves several of the major problems in literary hypertext, particularly the problem of dead branches or paths that lead nowhere. There is also no arbitrary repetition, although when you read Michael Joyce's Afternoon you can find purposeful repetition. I do have some repetition because I wanted the readers to come across a certain passage twice, but there is no accidental repetition. It also keeps track of how much left you have to read. 
So Literatronica always gives the reader viable options and optimizes the reading journey, though what is optimal depends on the preferences of the readers and the authors. Certain authors in electronic literature might pose resistance to that idea because they follow a modernist aesthetic. They write their works to be as fragmented as possible, continuously breaking narratological coherence. However, I think the system still sustain that as well.

TD: Taking a look at your location based narrative LA Flood Project, I was reminded of Richard Kostelanetz' work about New York and of the idea of "polyartistry". What kinds of art or artists have influenced your work? Do you feel yourself part of a tradition?

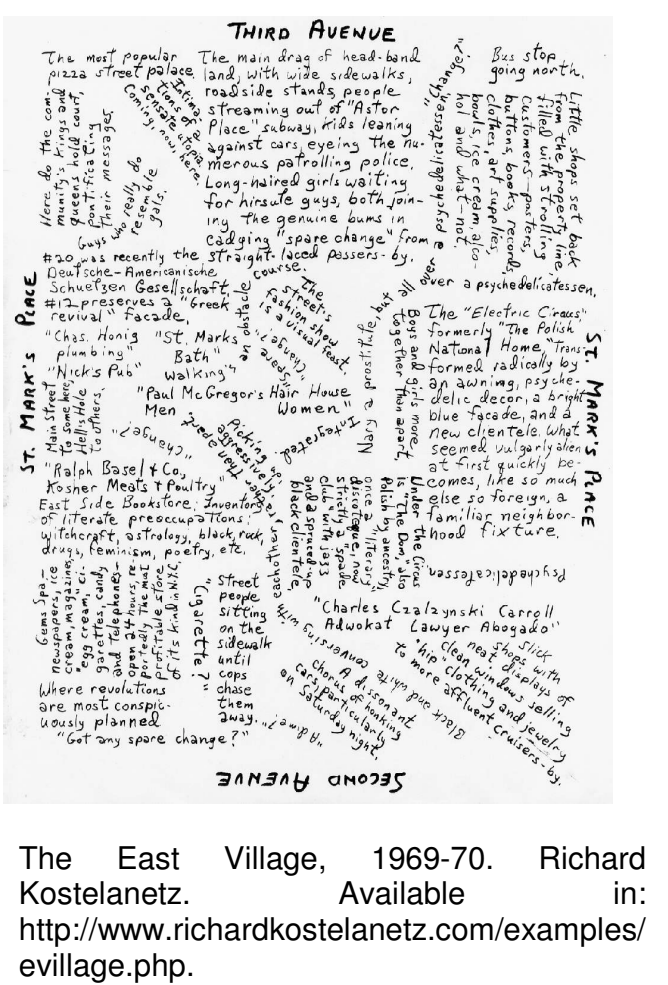

M. Marino: That project was influenced by the projects of two of the original creators: 34 North, 118 West, one of the first locative media narratives, and the Global Poetic System created by Juan B. Gutierrez and Laura Borràs Castanyer, which extended the Literatronica system to present literary paths through Barcelona. The nature of the piece, many voices from a city, is influenced by Anna Deveare Smith's Twilight: Los Angeles. I'd also tie this kind of project back to Rob Wittig and the Invisibles, whose Invisible Seattle presents a novel written by the people of Seattle. So the major threads would be: locative narrative and collaborative, multi-vocal location-based works in print.

In general, like a lot of experimental artists, l'm drawn to the Oulipo and other figures of the literary avant-garde. Borges, Cortázar, Calvino, Nabokov, the usual suspects. But form benders in general, Sterne, Cervantes. I think that I am part of the tradition of curious, sometimes 
silly, self-conscious form benders. I'm not sure this group has a name yet. Rob Wittig has helped me realize my debt to comedy, Monty Python, in particular. Douglass Addams. I'm in awe of Michael Ondaatje, the author of The English Patient. Julia Alvarez was a big influence on a show of

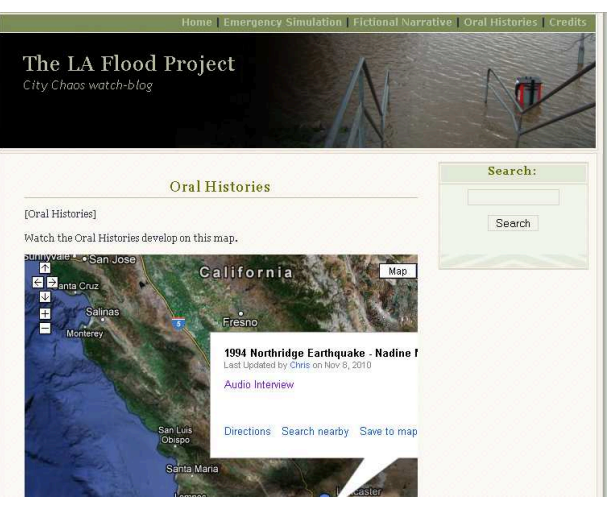
hands.

The great e-lit authors have also influenced me: Michael Joyce, Judy Malloy, MD Coverley, and Jaime Alejandro Rodríguez Ruiz.

TD: Regarding your mash-up "What the nightwoman texted", what difference does it make to use your own texts as raw material or somebody else's? Do you feel a "w-reader" or just an author using a collage technique?

M. Marino: The works in the Bunk Magazine/ Mad Hatters' Review Mash-up Issue were specifically made to be mashed, so "What the nightwoman texted" is less like, say, a collage of found art and more like a kind of collaboration or artists' game. These pieces speak to a new relationship of artists to their work - one in which they create knowing that they may be repurposed, excerpted, remixed, reconfigured.

Mark C. Marino

Masheur

what the nightwoman texted

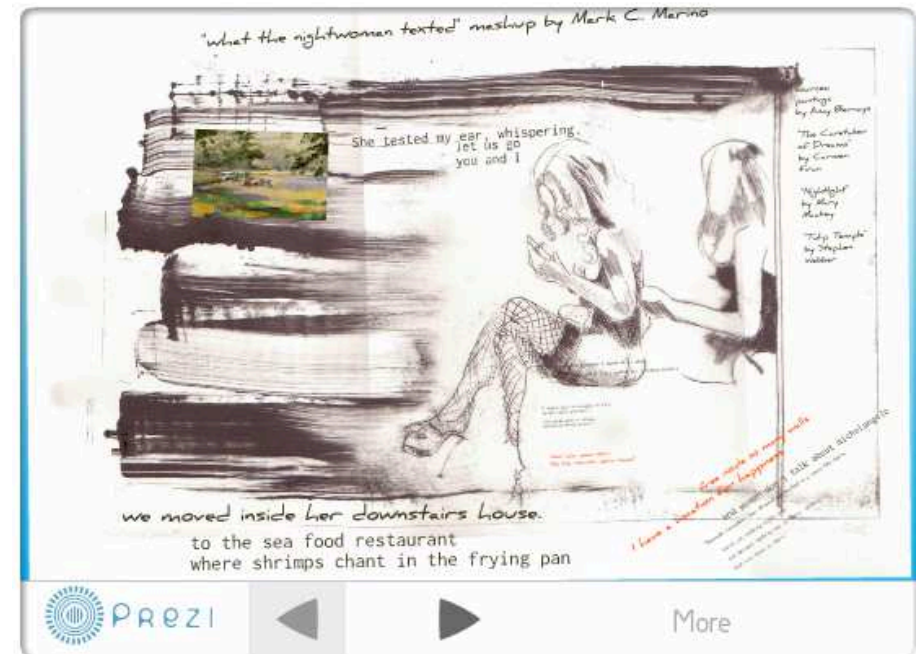


TD: Yes, I feel there is the drive underneath these collective works to incite the reader to do digital art himself or herself, something like what the Fluxus movement tried to do in the 1960s.

M. Marino: Yes, for example, among other features of this Mash-up Issue is a page ("You Mash Ours") with a list of works from different authors, and you can mash up any of these contents with each other. Jeremy Douglass' Mash-up, "e-lit cube", functions also as a kind of genre. He has set this up as filters in his computer, so that he can throw any text into these filters to create a new cube. It is done, I believe, using Quartz Composer, and you could throw your own texts into the structure of the cube and create your own version of it.

TD: Do you think general readers are prepared or trained to extract pleasure from digital literature or are they left blank, without coordinates to deal with it?

M. Marino: That probably depends on the reader, just as it would with any text. Authors of digital literature are often playing with the conventions of contemporary computer interfaces and practices - so by design, the average computer-using reader is well-situated for the encounter. The extraction of pleasure is another question entirely. You are asking, I think, "Is e-lit an acquired taste?" The most popular pieces are like wine, the gourmand and the drunk can appreciate them equally. Of course, training your pallet can lead to less gulping and more savouring.

TD: Maybe you could probably explain us here the basis of your "Critical code studies" since it is an approach to interpret electronic literature, among other things.

M. Marino: Critical Code Studies names a collection of approaches to digital objects through the entry point of the code. In works of e-lit in 
which you can access the code, this approach enables the critics to consider the relationship between the operating logic of the work and what the reader encounters. Jessica Pressman, Jeremy Douglass, and I are working on a reading of William Poundstone's Project for Tachistoscope in which I am offering a code reading to complement their examinations of the text and images. The code layer complements and complicates the other signifying channels.

TD: What kind of feedback do you receive from your readers? How do you use it?

M. Marino: For a show of hands, I received records of reading paths. This was the kind of surveillance feedback the Internet is so good at delivering. Like any good artist, I used it to fuel my neuroses. If you register for an account with Literatronica, the system keeps track of what you have read, so I can know something about the readers' experience, but it also tells me that dear friends have only read half of it even when they said they had enjoyed it entirely. So, those reader statistics showed me what pages people read, in what order, and how long they remained on each page, or at least kept each page open. Unfortunately, even those who had claimed to have read the entire work, rarely made it past 30 or 35 lexias.

My netprov collaborative projects, such as Grace, Wit, \& Charm, The LA Flood Project's Twitter feed, and the recent Last 5 Days of Sight and Sound, offer a much more productive form of feedback in the form of participation.

TD: Reading Marginalia in the Library of Babe/ I was struck by the great number of coincidences between your work and our interests as a group. We have read Borges' "The Library of Babel" with our students testing two models of digital annotation (DLNotes and @Note). Why do you think the study of marginalia has returned to the foreground of literary studies (if we could say so... we have noticed a proliferation of works in this respect, for example, the German 
University of Erfurt has organized two congresses already (2006-2008) solely dedicated to literary annotation)?

M. Marino: We are living in a technological moment where the affordance of annotation software is transforming our experiences, whether it is commenting on text or video or maps. Even the nowconventional content management sites, such as YouTube, offer commenting, which fulfils the role of at least one kind of marginalia. These same systems are also reacclimating us to the social dimension of annotation, that they are comments on comments. That online experience, from what I've seen, seems to be spilling back into our recognition of the crucial role of annotation and marginalia in all forms.

I created the piece Marginalia in the Library of Babel when I first encountered a piece of software called Diigo for book marking and social annotation of web pages. So I thought of creating a metafictional narrative using it. I have written the story of a character who is pursuing Borges on the Internet in these notes posted to real webpages (which I had to save so that the story would not be lost). Everything is somehow connected to Borges' story. So maybe Borges is a modernist and not a postmodernist, and maybe his story suggests totality of language, but it is closed. Whereas with the annotations I realized that there could be one more infinity built upon this, through marginalia. A lot of this is a reflection on the idea that everything has already been written and it can be contained on the internet, but now there is another convention that can expand it one step further. I think the piece that I've written is about the fact that the perfect library cannot exist, and that it is surely not the internet. The internet is a lot about loss, and absence, and loneliness...

TD: Do you think that digital literature will remain at the margins of the canon like it happened with visual or concrete poetry, or will it become the centre in the near-distant future? I guess that as Director of Communication for ELO you are working hard to disseminate electronic literature. Which are the strategies you are implementing? 
M. Marino: It feels like we're on the verge of something. The intersection of ebook readers, like the Kindle and Nook, with app-driven tablets and mobile phones, seems to be leading to a convergence, where readers are coming to expect more from text and seem delighted to get it. People are becoming more comfortable with interfaces and can even now take their computers to bed with devices that cuddle well. It feels closer than we've ever been to the great singularity of digital literature, but that has been said before.

My chief goal has been to help promote the sites for exploration, particularly the Electronic Literature Collections (<http://collection.eliterature.org $>$ ), the Electronic Literature Directory (<http://eld.eliterature.org>), and the ELMCIP knowledge base. And of course there are a growing number of databases around the world. We're also redesigning <http://eliterature.org $>$ to make it a more robust hub of activities. On a more public side, I try to monitor discussions of digital narratives and try to intervene and tell people about the works that are out there. But, in my experience, the spread of e-lit happens more through people, teachers like you, friends, and publications like this one.

TD: Thanks a lot, Mark, for this interview and for sharing so many ideas with us. We will keep track of your future books. For our readers' knowledge, we direct them to two of your future book projects, in case they are interested in learning more about how you apply Critical Code Studies to digital objects, and digital literature in your second book:

\section{10 PRINT CHR $\$(205.5+R N D(1)) ;:$ GOTO 10}

Nick Montfort, Patsy Baudoin, John Bell, lan Bogost, Jeremy Douglass, Marc C. Marino, Michael Mateas, Casey Reas, Mark Sample and Noah Vawter. MIT Press. [Due out this winter]:

$<$ http://mitpress. mit.edu/catalog/item/default.asp?ttype=2\&tid=13015> 
This book takes a single line of code--the extremely concise BASIC program for the Commodore 64 inscribed in the title-and uses it as a lens through which to consider the phenomenon of creative computing and the way computer programs exist in culture. The authors of this collaboratively written book treat code not as merely functional but as a text--in the case of 10 PRINT, a text that appeared in many different printed sources--that yields a story about its making, its purpose, its assumptions, and more. They consider randomness and regularity in computing and art, the maze in culture, the popular BASIC programming language, and the highly influential Commodore 64 computer.

2. CLOSE READING ELECTRONIC LITERATURE, A CASE STUDY: William Poundstone's 'Project for the Tachistoscope: [Bottomless Pit]' Jeremy Douglass, Mark C. Marino, Jessica Pressman. [Due out in a year].

This book presents a case study for developing digital humanities methods of literary interpretation by close reading a born-digital literary work from three radically different methodological perspectives. Jessica Pressman reads the onscreen aesthetics, Mark Marino practices Critical Code Studies and analyzes the programming code, and Jeremy Douglass uses cultural analytics to show how data-visualizations stimulate literary interpretations. Together they collaborate in scholarly hermeneutics, weaving our interconnected questions into shared understanding while arguing that such transdisciplinary approaches provide the multiple perspectives necessary to illuminate digital poetics.

Texto recebido em 19/06/2012 